Marks, Laura U. 2000. The Skin of the Film: Intercultural Cinema, Embodiment, and the Senses. Durham, NC: Duke University Press.

- 2002. Touch: Sensuous Theory and Multisensory Media. Minneapolis: University of Minnesota Press.

McMahon, Laura. 2012. Cinema and Contact: The Withdrawal of Touch in Nancy, Bresson, Duras and Denis. Oxford: Legenda.

Merleau-Ponty, Maurice. (1945) 1962. Phenomenology of Perception. Trans. Colin Smith. London: Routledge.

. 1961. The Visible and the Invisible. Trans. Alphonso Lingis. Evanston, IL: Northwestern University Press.

Moi, Toril. 1985. Sexual/Textual Politics: Feminist Literary Theory. London: Routledge.

Nussbaum, Martha. 1990. Love's Knowledge: Essays on Philosophy and Literature. New York: Oxford University Press.

Pick, Anat. 2013. "Three Worlds: Dwelling and Worldhood on Screen." In Screening Nature: Cinema Beyond the Human, ed. Anat Pick and Guinevere Narraway, 21-36. Oxford: Berghahn.

Quinlivan, Davina. 2012. The Place of Breath in Cinema. Edinburgh: Edinburgh University Press.

Sartre, Jean-Paul. (1943) 2003. Being and Nothingness: An Essay on Phenomenological Ontology. Trans. Hazel E. Barnes. London: Routledge.

Sobchack, Vivian. 1991. The Address of the Eye: A Phenomenology of Film Experience. Princeton, NJ: Princeton University Press.

- 2004. Carnal Thoughts: Embodiment and Moving Image Culture. Berkeley: University of California Press.

Wilson, Emma. 2012. Love, Mortality and the Moving Image. Basingstoke: Palgrave Macmillan.

Young, Iris Marion. 1980. "Throwing Like a Girl: A Phenomenology of Feminine I Body Comportment; Motility and Spatiality." Human Studies 3(2):137-56.

\title{
Resistances of Touch
}

\section{Cathryn Vasseleu}

Dychedelic drugs and sexual freedom were not the only preoccupations of Western youth in the 1960s. Coinciding with global eruptions of political activism, there was an outpouring of innovation in art. This was the climate in which a feminist art movement emerged with a far-reaching activist agenda of its own to contribute: the radical transformation of Western art history through politically inflected questionings of its basic tenets. In pursuit of this agenda many feminist artists were drawn to

[Signs: Journal of Women in Culture and Society 2015, vol. 40, no. 2]

(C) 2014 by The University of Chicago. All rights reserved. 0097-9740/2015/4002-0004\$10.00 
forms of body art or live performance centered on the artist's physical presence. Defying a primarily visual aesthetic tradition that lent itself to the formal appreciation of women's bodies by a notional viewing subject, live performance incorporated the materiality and multiple sensory modalities of perceptual experience, touch in particular. The deployment of such strategic inquiry arguably wrought far-reaching changes in thought about subjectivity, extending beyond gender to racial difference and ethnicity. Can the same be said of the impact of these strategies on stereotypes of gender based on tactile perception - that they demolished outdated characterizations of subjectivity in terms of touch?

Whether there is an inherent connection between feminine subjectivity and touch or whether the connection is a cultural construct is a complex topic of debate within feminist theories of perception. However, prior to this debate what mattered to feminist performance artists was how they might wield the connections between touch, femininity, and art as a weapon in their quest to expose the fallacy of the neutral perceiving subject. While nineteenthand early twentieth-century feminism had sought to establish women's legal rights and equality, in the 1960s the focus of feminism widened to an interrogation of all areas of women's lives, including their experience of sexuality, race, ethnicity, family, work, and technology. However, because of the apparent absence of a material referent, visual aesthetic traditions operated in denial of such variables in perceptual experience. Tactile perception offered one possible source of resistance to the myth of gender neutrality (and racial, ethnic, class, or other forms of neutrality) perpetuated by a notional subject of vision. Broadly speaking, feminist artists latched onto the fact that touching pertains to a bodily act and affect, not a bodiless presence devoid of social and historical context or cultural standing.

In resisting the notional subject of vision by incorporating tactile perception, live performance led feminist art practice in a new direction; it began engaging in resistances pertaining to the dynamics of touch. There are resistances to touch in the psychoanalytical sense of resistance as defense or repression. Feminist live performance artists such as Yoko Ono and Marina Abramović were dealing with issues that went beyond that. What they encountered and presented to audiences were entrenched characterizations of subjectivity in terms of touch that feminist art history, theory, and practice needed to critically address. In the process they also encountered resistances of touch. I am referring here to structural resistances of tactual knowledge (practices of all kinds invested in and operating through touch) to conceptual, aesthetic, or political revisions that in their very framing result in distortions, mixed outcomes, or failed intentions. Even live performances that worked directly through physical contact, dramatizing touch in an unscripted 
way, participated in resistances of touch, understood as insensitivity, being unaffected, holding back, or impedance.

Women artists associated with avant garde movements (including Dada and surrealism) had previously produced art objects that worked by addressing and engaging creatively with tactile sensations. First to be acknowledged as such was Edith Clifford Williams's 1916 sculpture Plâtre à toucher chez de Zayas (Plaster for touching at de Zayas), intended for touching, which Guillaume Apollinaire named as the inaugural work of an art form whose birth he announced in 1917 (Apollinaire 1917, 1918). Subsequent artists experimented with types of tactile art that were not necessarily intended for touching but that, even in their visual reception, deliberately aroused accidental or unconscious tactile associations, sometimes subversively related to gender (e.g., Méret Oppenheim's iconic 1936 Fur Dinner Suite). The fundamental innovation live performance artists introduced in relation to this avant garde legacy of tactual experimentation was to turn to their own bodies (and also the audience's) as the primary medium in which they worked.

A loose thread linking many creative practices concerned with tactual experience is the objective of overcoming fossilized aesthetic values through a renewed sensibility and awareness of touch. From its inception the agenda of feminist performance extended to touch. However, this was primarily in relation to a more recognizable political agenda concerned with gender, which an art practice centered on a woman's body typified and enacted. On the cusp of the era of digital-electronic media, it was widely appreciated that new forms of communication entailed a metamorphosis in perception generally, along with the definition of art, cinema, theater, and so on. Indeed, the significance of touch per se in feminist performance from the 1960s to the 1980s was not emphatically articulated until Peggy Phelan dwelt specifically on the wider ramifications of insights gleaned from tactile interactions across a range of examples (2007). In other words, as a consequence of centering on a performer's body, a critical tactual dimension or realm of knowledge could be strategically brought into play. This provoked reevaluations of touch, not only in relation to aesthetic values but also in relation to rethinking gender. Tactual knowledge manifestly complicated the unstated rules of engagement of media, the intrusions of technologies, art and aesthetics, in gender politics. Notably, however, working through touch in this way did not automatically ensure that the outcome would benefit either women artists or the causes of feminism.

VAliE EXPORT's 1968 performance Tapp und Taskino/Tap and Touch Cinema at an experimental film festival in Vienna is a classic case in point. Elaborating on feminist actionism (EXPORT 1989) and the concept of ex- 
panded cinema, EXPORT donned a miniature movie theater composed of a box with an opening at the front covered by curtains. She then wandered the streets nearby, inviting passersby to put their hands between the curtains and feel her naked breasts inside. In the process, according to ExPORT, "the curtains which previously had been drawn up only for the eyes are also finally raised for the hands. Tactile reception counteracts the fraud of voyeurism" $(2003,4)$. An exposé of fantasies of female flesh underpinning and sanctioned by cinema, Tap and Touch Cinema was designed to subvert social prescriptions governing "the intimate sphere of what the state permits" $(2003,4)$ by forcing it into the open, into public space where women and children too could indulge in a pleasure that would otherwise be taboo for them.

The performance succeeded in enticing both men and women to expose themselves to the gaze of others, including the artist, while they took tactile pleasure in her cinema. However, the setup also revealed that neither voyeuristic agency nor any other kind of reversal of subjectivity transferred to the artist while participants felt her breasts. Nevertheless, ExPORT's assessment of her mobile touch cinema was that it was "an unveiled intrusion into the taboo of homosexuality" and indeed "the first real women's film” (2003). Phelan's assessment of its success was more mixed and thus invites closer study. On the positive side, EXPORT's performance exposed the blindness of traditional and some avant-garde film practices, "which continually reproduced the voyeuristic structure of the man of action and the woman as object to be seen" $(2007,359)$. But once exposed, "the political transformation that should have logically followed this insight stalled" (359). By way of a more encouraging verdict on the factors limiting EXPORT's enterprise, Phelan connects her nevertheless groundbreaking work to subsequent psychoanalytically informed analyses of sexual difference and models of the gaze by feminist filmmakers and artists.

The lesson of Tap and Touch Cinema was unambiguous. No political transformation. No logical conclusion. A transfer of power undeniably stalledimpeded-resisted. Even so, a question still remains that goes to the heart of EXPORT's daringly playful, unforgettable model of cinema: its investment in direct physical contact or, in ExPORT's words, "tactile reception" $(2003,4)$. Is it possible that the intention of Tap and Touch Cinema not only succeeded but also stalled precisely because of its reliance on touch as a corrective?

In Tap and Touch Cinema EXPORT drew on her knowledge of touch, which included knowing that women as well as men can take pleasure in touching women's breasts. Despite her use of this knowledge as a revisionary measure, placing her own breasts in the juncture of an open invi- 
tation to touch while being watched touching, there was no equivocal contact. She became a touchable object, not a watching subject touching back. The gesture inadvertently reproduced the formal contradictions of touch: touchable versus untouchable, violable versus inviolable. These contradictions condition voyeuristic pleasure, and although not innately gendered, it has long been recognized that their gendering is the foundation of innumerable determinations of the attributes of feminine subjectivity (touchable, violable) versus masculine subjectivity (untouchable, inviolable). In Tap and Touch Cinema a woman's knowledge of touch subverted the implicit gender of the voyeur-subject, but the performance also met with the voyeur-subject's intolerance of being affected uncontrollably by indiscriminate contact. Voyeurism is a scenario that, as Tap and Touch Cinema revealed, involves the delineation of a subjectivity that is untouchable, inviolable, even when in direct contact with that which is viewed. Counteracting voyeurism with tactile reception did not subvert - and was indeed subverted by - the termination of touching in the formal contradictions of touch that enable voyeuristic pleasure.

EXPORT and other live performance artists of the time were followed by theoretical analyses of the contradictions they had unflinchingly negotiated in pursuit of their vocation. The resistances of touch that these artists explicated through their often physically perilous engagements in tactual inquiry kept their political agenda alive; they helped to transform not only feminist art practice but also theories of perception, awareness of tactual knowledge within the humanities, and the widespread exercise of touch across a variety of media. They also showed that while there are many ways for artists to work tactually, touching is affected by structural resistances, which means that it is not possible to work in an inherently tactual way.

University of Technology, Sydney

\section{References}

Apollinaire, Guillaume. 1917. "Mon Cher Ludovik" [My dear Ludovik]. In Almanach des Lettres et des Arts [Almanac of arts and letters], 497-99. Paris: Martine, Choses à la Monde.

- 1918. "L'Art Tactile" [Tactile art]. Mercure de France [French mercury], February 16, 751-53.

Export, Valie. 1989. “Aspects of Feminist Actionism.” New German Critique 47 (Spring/Summer): 69-92.

2003. "Expanded Cinema as Expanded Reality." Senses of Cinema, no. 28. http://sensesofcinema.com/2003/28/expanded_cinema. 
Phelan, Peggy. 2007. "The Returns of Touch: Feminist Performances, 1960-80." In WACK! Art and the Feminist Revolution, ed. Cornelia Butler and Lisa GaI brielle, 346-61. Cambridge, MA: MIT Press.

\section{Subversive Uses of Perception: The Case of Palestinian Artist Anisa Ashkar}

\section{Tal Dekel}

$\mathrm{F}$ rom the very beginning of her career, artist Anisa Ashkar (born in 1979) has fought a conscious battle against categorization, labeling, and compartmentalization. Focusing on the "minor" senses of smell and touch, she has sought to undermine cultural constructions - such as feminine and masculine, Israeli and Palestinian-by insisting on expressing her own multiple and shifting identities: ${ }^{1}$

I start my works with a gut feeling, avoiding any rational analysis. I taste and smell, I rub materials onto the skin, feeling them on my body. Only then do I engage in a reflexive process about the piecea very important aspect. Although the deep political, ethnic, religious, and gendered meanings are all there, I only conceptualize them retrospectively. Our culture perceives intuitiveness-relying on the senses - as primitive, feminine, antirational, inferior, and unreliable in comparison with the transcendental qualities of rationality, perceived as masculine. .. A Also, using the "minor" senses serves me in order to symbolize my being a minority in many additional meanings. . . . I am ever-changing, depending on where I'm at. ${ }^{2}$

I would like to thank Anisa Ashkar for sharing with me her work and deep knowledge and understanding.

${ }^{1}$ The traditional five senses have usually been arranged in terms of a hierarchy that assumes vision to be primary, hearing second, followed at a considerable remove by touch, taste, and smell. Especially since the Enlightenment, seeing and knowing have been equated, largely because sight can operate at a greater distance than the other human senses and is therefore considered the most objective. With the mind and body regarded as separate, sight was associated with the mind, with reason, rationality, and logic; by contrast, taste, touch, and smell were associated with the body as the source of unreason, the emotions, and irrationality (Dumcum 2012, 184).

${ }^{2}$ Throughout this article I include quotations from an interview I conducted with Anisa Ashkar at her Tel Aviv studio on June 16,2013. The interview was conducted in Hebrew and was translated into English by me.

[Signs: Journal of Women in Culture and Society 2015, vol. 40, no. 2]

(C) 2014 by The University of Chicago. All rights reserved. 0097-9740/2015/4002-0005\$10.00 